\title{
Teaching geometry in schools: an investigative rather than instructive process
}

\author{
Rasheed Sanni \\ University of the Witwatersrand \\ Email: riosan1@yahoo.co.uk
}

\begin{abstract}
Research has documented the prevalence of lessons characterised by homework check, followed by teacher lecture and demonstration, followed in turn, by learner practice sequence of classroom instructional activities in our classrooms. This sequence of classroom activities does not allow for the development of sound mathematics practices and mathematical proficiency. Meanwhile, curriculum reforms in South Africa as well as in other parts of the world recommend classroom activities where teachers create opportunities for, listen to and extend learners. This paper presents a sequence of activities to be used in the teaching of geometry and surface areas of solid shapes in a grade 8 classroom. The sequence portrays the teaching of these concepts as an investigative rather than instructive process.
\end{abstract}

\section{Introduction}

Outcomes-based education (OBE) is the foundation for Curriculum 2005 (C2005) in South Africa, and guides curriculum development and learning outcomes based on critical and developmental outcomes. According to the Department of Education policy documents, critical outcomes require learners to be able to

(1) identify and solve problems and make decisions using critical and creative thinking; (2) work effectively with others as members of a team, group, organisation and community; (3) organise and manage themselves and their activities responsibly and effectively; (4) collect, analyse, organise and critically evaluate information; (5) communicate effectively using visual, symbolic and/or language skills in various modes; (6) use science and technology effectively and critically showing responsibility towards the environment and the health of others; and (7) demonstrate an understanding of the world as a set of related systems by recognising that problem-solving contexts do not exist in isolation (Department of Education, 2002a).

To achieve these, the Revised National Curriculum Statement emphasises a learnercentred, activity-based approach to the teaching of mathematics. This is clearly the tone in the set learning outcomes and assessment standards at various phases of the different grade levels of the educational system. It identifies the following learning areas, which include interrelated know- ledge and skills, on the basis of which learning outcomes and subsequent assessment standards are set. The knowledge areas include, (1) numbers, operations and relationships; (2) patterns, functions and algebra; (3) space and shape (geometry); (4) measurement; and (5) data handling. Skills include, (1) representation and interpretation; (2) estimation and calculation; (3) reasoning and communication; (4) problem-solving and investigation; and (5) describing and analysing (Department of Education, 2002b). A critical look at these will reveal some positive relationships between the curriculum and either of the RAND Mathematics Study Panel's (2002) mathematics practices and Kilpatrick, Swafford and Findel's (2001) strands of mathematical proficiency. It then suggests that the provisions of the curriculum are strong enough to evolve the doers of mathematics that would exhibit mathematics practices and proficiency in mathematics, within and outside of the classroom.

However, the sequence of mathematics classroom practices which research has documented to be prevalent in our classrooms entails checking homework, followed by teacher lecture and demonstration, followed in turn by learner practice in a sequence of classroom instructional activities. This is unfortunately neither that which the curriculum proposes, nor that which allows for the attainment of the laudable outcomes. This explains why learners would tell almost spontaneously that the area of a rectangle 20,000 metres by 20 metres is 400,000 square metres, but could not find out how much land has to be taken from a cocoa plantation in order to build a 20-km-long 2-lane highway within the plantation; or a learner can successfully find the surface area of a cuboids 
$10 \times 8 \times 10 \mathrm{~cm}$ in class, but cannot help her mother estimate the number of one-metre square tiles required to cover the walls and floor of her (mother's) shop which is $10 \mathrm{~m}$ long, $8 \mathrm{~m}$ wide and $10 \mathrm{~m}$ high. This issue of discontinuity between school learning and cognition out of school is observed by Resnick (1987, in Engestrom, 1996) thus:

The process of schooling seems to encourage the idea that the "game of school" is to learn symbolic rules of various kinds, that there is not supposed to be much continuity between what one knows outside school and what one learns in school. There is growing evidence then that not only may school not contribute in a direct and obvious way to performance outside school, but also that knowledge acquired outside school is not always used to support inschool learning. Schooling is coming to look increasingly isolated from the rest of what we do. (p 151)

As a means of overcoming this, curriculum reforms, especially in the new South Africa, create more challenging responsibilities for the teachers and generally call for change. For instance, it has been widely recognised that traditional mathematics teaching emphasises and encourages memorisation and application of algorithm and procedures. Procedural fluency is only one of five strands of mathematical proficiency. Others, such as conceptual understanding, strategic competence, adaptive reasoning and productive disposition (Kilpatrick et al. 2001) are not emphasised, nor are RAND Mathematics Study Panel's (2002) repressentation, justification and generalisation skills focused on in traditional teaching. Provisions and demands of the new South African curriculum suggest a drastic change from traditional modes of teaching to reform (learner-centred) teaching, which focuses on the nurturing of proficiency and development of mathematical practices. It is therefore imperative that ways are found not only to suggest changes in teachers' practices, but also to provide necessary support and assistance for such desired changes to manifest in the classroom. One such mode of support is through the presentation of lessons that support the nurturing of proficiency and development of mathematical practices in learners, which is the focus of this paper.

\section{Investigative teaching of geometry}

Research findings have shown that learning is enhanced by their engagement with relevant materials, even if learners have certain learning difficulties (Bransford, Brown \& Cocking, 1999; Mastropieri \& Sruggs, 1992). Hence, the situated theorist's position is that everybody will learn if given an enabling environment to participate in a community of practice. This is similar to the calls by Brown, Collins and Duguid (1989), Hanks (1991) and Lave (1996), that learning is enhanced through participation of individual learners - a process referred to as enculturation and apprentice-ship. All these point to the importance of learners' active participation in instructional process.

Abraham's (1997) learning cycle is an inquirybased teaching approach, developed for science teaching, which I have found useful in investigative teaching of concepts in geometry and indeed in other areas of mathematics. The approach, which derives from the cognitivist and constructivist position on teaching and knowledge-seeking, divides instruction into four progressive stages. Step one is engage, where the teacher creates an enabling environment to engage learners in activities that generate curiosity and interest in the planned topic of the day. Usually, an inquiry question is presented to the learners at this stage.

The second stage is explore, where learners explore the question(s) raised at the engage stage and generate answers. At this stage, the learners are placed in groups, and the teacher acts as a facilitator and usually asks further questions to guide learners' explorations, and provides hints about how to proceed, without showing learners "exactly how to go about solving the problem" (Stein, Smith, Henningsen \& Silver 2000). Usually, this stage is characterised by a series of questions and introductory activities that are similar to the topic presented in their worksheets (see Appendix 1 and 2).

Then comes the third stage, explain, where opportunities are provided for learner groups to present solutions or answers to the inquiry question(s), giving justifications and explanations for their claims. And then comes the last stage, extend, where learners extend their concepts and skills to other situations by applying what they have learned in the explain stage. Usually, and particularly so in mathematics, further tasks in which these skills can be exhibited are provided for the learners. It could be in groups, pairs, or individually. At each of these stages, and indeed at the end, evaluation of the process would go on simultaneously.

It is important to note that activities at all of these stages are interlinked, and will bring about learners' active participation. This emphasis represents an important merger between mathematics as an investigation and mathematics as a body of knowledge, where learners acquire "knowledge through 
investigation and experimentation in order to facilitate verbalising, understanding and applying principles in the real world"' (Luera, Killu \& O'Hagan, 2003: 195). According to Freudenthal (1991), mathematics must be connected to reality. It is through this approach that the learners can develop and apply mathematics to problem that makes sense to them (Van Den Heuvel-Panhuizen, 2003; Wigley, 1994; Freudenthal, 1991).

Below, I provide an example of a learner-centred, inquiry-based investigative lesson in a unit of mathematics in the space and shape (geometry) learning area of C2005. This unit is chosen because of its applicability to all learners, especially from grade level 7 through to 12 , and because elements of it are discernable from the assessment standards at these levels. More importantly, it has been used because learners find it difficult to understand description of surface areas, even though this is one of the most physical ways of describing an object.

\section{Skills required}

\section{Lesson Description}

- Length measurement.

- Addition and multiplication of numbers.

- Unit analysis.

Lesson objectives

By sustained investigation, inquiry-learning activities, the learners will be able to:

- Describe the concept of surface area.

- Explain the features of a shape that influence its surface area.

- Measure different edges of a prism.

- Decouple regular prisms and identify the different planes in it.

- Find the area of the composite surfaces.

- By addition, compute the surface area of solids.

- Generate and use mathematical equations to compute surface areas of plane shapes and other possible variables in them

\section{Materials needed}

- Three cardboard boxes of 3 different sizes - A: $5 \times 4 \times 6 \mathrm{~cm}$; B: $2 \times 3 \times 5$ $\mathrm{cm}$; and C: $4 \times 4 \times 7 \mathrm{~cm}-$ and their nets, for different learner groups.

- Rulers.

- $1 \times 1 \mathrm{~cm}$ square rubber tiles or stickers.

- $1 \times 1 \mathrm{~cm}$ square dotted papers.

- Scissors.

- Gum.

\section{Lesson presentation}

Engage

This stage requires the teacher's initiative in presenting a relevant scenario that would arouse learners' curiosity and stimulate their interest in getting involved. I consider the one below for the lesson:

Christmas is approaching and Mr White and his family have decided to make their living room wear a new look. John, a member of the family, came up with an idea: "tiling the walls and floor would be good." "That's nice, sky blue walls and light brown glittering floor," says his sister Flo. "How many tiles will we need?" asked Mr White.

The teacher then poses the following question to the class: How many wall tiles, floor tiles would be needed to make the living room, $8 \frac{1}{2}$ metres long, 7 metres wide and 3 metres high, wear a new look? Assume that they are using tiles that are 0.5 by 0.5 metres, and packaged in packs of 10 tiles. If a pack of floor tiles sells for R135 and a pack of wall tiles sells for R110, estimate the cost of the required tiles.

The inquiry question here is to determine the number of tiles required and then the cost. The learners are supposed to work in groups of 4 and the teacher circulates and provides guidance but never tells them the way to go about it.

\section{Explore 1}

At this stage, learners in their various groups discuss ideas that emerge within the groups as they attempt to work through worksheet 1 (see Appendix 1). They engage in different forms of activities using the materials provided. These activities are guided by the teacher and especially through work-sheet 1 . Once learners have worked through the worksheet successfully, the class is ready to move onto the next stage.

\section{Explain 1}

This is the stage where learners discuss their solution to the problem in worksheet 1. This should be done by a presenter from each group, and detailed explanation and justification should be demanded. The teacher should ensure this by pressing other learners to ask questions and specifically demand explanations. Before the end of this plenary session, the teacher should ensure that an interaction evolves in which learners realise the importance of nets of shapes in mathematical explorations. This leads to the main problem in Explore 2. 


\section{Explore 2}

Exploration continues in this stage. As in explore 1, activities are guided by the teacher and especially with worksheet 2 (Appendix 2). The inquiry question in this exploration is to determine the number of tiles that the Whites will need, and the cost. An important question regarding the door and windows in the living room will possibly erupt as learners work through this worksheet. Depending on the learners' level of competence, the teacher may find it necessary to advise them to ignore this detail in working on the number of tiles required for the wall. Learners should be given free hand to approach this exercise by counting squares on the square paper or by fixing squares stickers on the net. More competent learners may even recognise the pattern and choose to compute the areas. They might work in their original groups or in pairs.

\section{Explain 2}

This is the stage where learners discuss their solution to the original problem in a plenary session. Presentation should be done by a different presenter from each group, and detailed explanation should be demanded. As in explain 1, the teacher needs to ensure that logical explanations or justifications are given for the position taken by different groups. Pressing them and specifically demanding explanation will do this. One or two groups might notice the linkages to a pattern relating to the area of rectangles.

During the learners' presentations, the teacher should guide the learners in understanding that the number of 1-by-1 squares that a plane surface can take is referred to as, the 'surface area of the plane surface'. Furthermore, where two or more plane surfaces combine to form a shape, then the surface area of that shape is obtained by summing the surface areas of all the plane surfaces involved. The latter is what is referred to as, "total surface area'.

\section{Extend}

Here, an extension of concepts and generalisations of ideas is necessary. Learners infer from the group presentations that the surface area of a rectangular prism is a function of its length, breadth and height, or its base area and height. Using the two activities, the teacher should now show how the work relates to (i) length, breadth and height, and (ii) base area and height. This can then be used to generalise an equation for the surface area of a rectangular prism, and perhaps other prisms (triangular base, cylinder, etc), depending on the learners' level of competence.

Learners might now be asked to find the number of tiles that will be required:

(i) to cover the walls of a company's warehouse that is 25 metres long, 15 metres wide and 12 metres high.

(ii)both inside and outside of a regular hexagonal reservoir with an outer measurement of 10 metres long and 20 metres high, assuming the thickness of the wall is one metre.

This could be done in pairs. To further extend knowledge in this area, learners could do a project using buildings within the school, or beyond, where the teacher has identified shapes that are not rectangular but some other geometrical shape like a trapezium, or has other fixtures like fireplaces or alcoves.

\section{Explain 3}

This phase allows the learners to approach surface area problems without having to engage in practical counting of squares. It should be noted that some of the pairs might still approach task (i) by disjointedly computing the areas of the walls and summing up. This is fine, but the teacher needs to help the learners link the two tasks in a logical manner, especially if some of the class have already approached the solution holistically. An attempt at task (ii) above, and the project that follows, should actually be commended and appreciated. In fact, this could generate lengthy

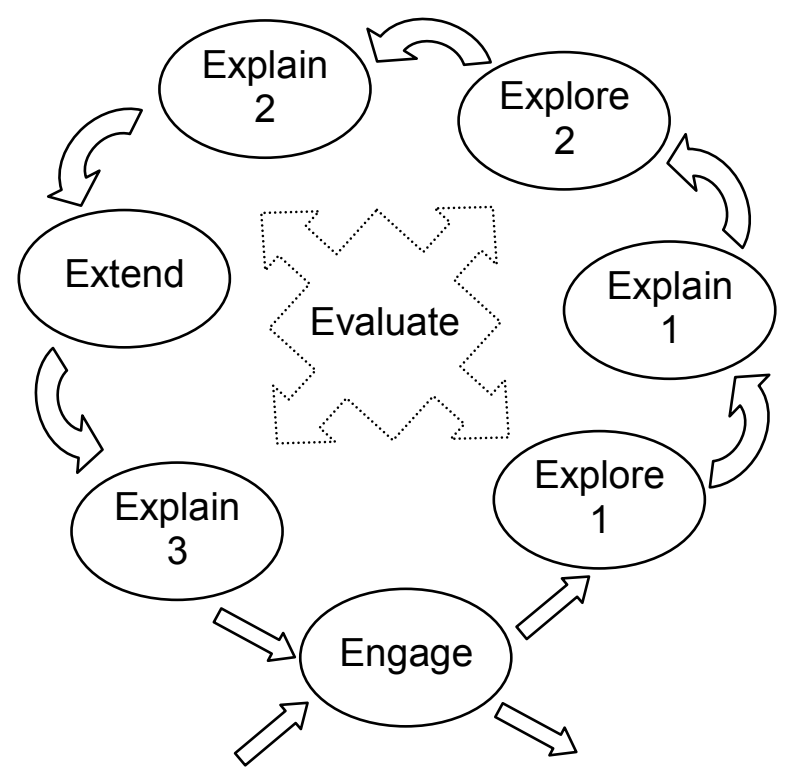

Figure 1. Investigative learning (adapted from Luera et al.'s (2003) inquirybased learning cycle 


\section{Rasheed Sanni}

discussions, based on shapes and fixtures that learners find and bring to class. Such discussions could provide the inquiry question for the next lesson (Figure 1).

\section{Evaluation}

Although, there ought to have been some form of evaluation at each of the different levels above, it is imperative that learners be asked questions or given tasks that allow a further demonstration of knowledge, like tasks (i) and (ii) and the suggested project on the previous page. This could be in another worksheet or textbook, or tasks earlier identified and selected by the teacher for that purpose. It is important that such tasks cover a variety of possible scenarios that learners might face in real life situations, within or outside of the school, and even in different units of measurement. These tasks should be handed in, graded, returned and discussed in class because, according to Piaget (1964) and other cognitivists, the discussion that learners' responses generates is even more important than the questions asked by the teacher or tasks set up and implemented in the classroom.

\section{Conclusion}

The foregoing scenario is an illustration of application of Abraham's (1997) learning cycle in the planning and implementation of mathematics lessons. Although it is widely used in science teaching, it is equally useful in teaching mathematics. The approach explicates the teaching of geometry as an investigative rather than instructive process. An investigative approach to teaching ensures adequate teacher preparation for the lesson, offers opportunities for learners to recognise previous knowledge, and accommodates learners' alternative conceptions. Hence, it provides learning experiences that help them to revise alternative notions and develop new concepts, and ensures adequate involvement in the lesson. Also, according to Lorsbach (2002), it naturally leads to other investigations that promote further exploration of other mathematical concepts. It therefore appears that one way for mathematics teachers to exemplify the current reform in mathematics teaching is for them to teach the subject via the learning cycle. This emphasises an investigative rather than instructive mode of instruction that will enhance the nurturing of all five strands of mathematical proficiency and develop mathematical practices.

\section{Acknowledgements}

I wish to acknowledge, with sincere gratitude, the quality of supervision and mentorship I enjoy from my supervisor, Professor Karin Brodie. I also acknowledge the financial support that I receive from the Mellon Foundation and National Research Foundation towards my doctoral research, out of which this study and paper stemmed. Finally, the professional support we get from other members of staff in the Marang Centre for Mathematics and Science Education at Wits is acknowledged and appreciated.

\section{References}

Abraham, M. (1997). The learning cycle approach to science education. Research Matters - to the Science Teacher. Retrieved March 10, 2005, from http://www. narst.org/research/cycle.htm

Bransford, J., Brown, A. \& Cocking, R. (Eds.) (1999). How people learn: Brain, mind, experience and school. Washington, DC: National Research Council.

Boaler, J. (1997). Experiencing school mathematics: Teaching styles, sex and setting. Buckingham: Open University Press.

Brown, S.J., Collins, A. \& Duguid, P. (1989). Situated cognition and the culture of learning. Educational Researcher, 18(1), 32-41.

Department of Education. (2002a). Introducing the mathematics learning area. In Revised National Curriculum Statement Grades R-9 (Schools): Mathematics (pp 4-6). Pretoria: Department of Education.

Department of Education. (2002b). The senior phase. In Revised National Curriculum Statement Grades 10-12 (Schools): Mathematics (pp 61-91). Pretoria: Department of Education.

Engestrom, Y. (1996). Toward overcoming the encapsulation of school learning. In H. Daniels (Ed.), An Introduction to Vygotsky. Chapter 6 (pp 143-150). London: Routledge.

Freudenthal, H. (1991). Revisiting mathematics education. Dordrecht: Kluwer Academy.

Hanks, F. (1991). Foreword by William F. Hanks. In J. Lave \& E. Wenger, Situated learning: Legitimate peripheral participation (pp 13-24). Cambridge: Cambridge University Press.

Kilpatrick, J., Swafford, J. \& Findel, B. (Eds.) (2001). Adding it up: Helping children to learn mathematics. Washington DC: National Academy Press.

Lave, J. (1996). Teaching, as learning in practice. Mind, Culture and Activity, 3(3), 149-163. 
Lorsbach, A. (2002). The learning cycle as a tool for planning science instruction. Retrieved March 10, 2005, from: http://www.coe.ilstu.edu/scienceed/ lorsbach/2571rcy.htm

Luera, G. R., Killu, K. \& O’Hagan, J. (2003). Linking math, science and inquiry-based learning: an example from a mini-unit on volume. School Science and Mathematics, 103(4), 194-202.

Mastropieri, M.A. \& Sruggs, T. E. (1992). Science and students with disabilities. Review of Educational Research, 62, 377-411.

National Council of Teachers of Mathematics (2000). Principles and standards for school mathematics. Reston: VA: National Council of Teachers of Mathematics.

Piaget, J. (1964). Development and learning. In R. E. Ripple \& V. N. Rockcastle (Eds.), Piaget Rediscovered. Ithaca: Cornell University Press.

RAND Mathematics Study Panel (2002). Mathematical proficiency for all students: Towards a strategic research and development program in mathematics education (pp 24-35). Arlington, VA: RAND Education, Science and Technology Policy Institute.

Stein, M., Smith, M., Henningsen, M. \& Silver, E. (2000). Implementing standard based mathematics instruction: a casebook for professional development. New York: Teachers College Press.

Van Den Heuvel-Panhuizen, M. (2003). The Didactical use of Models in Realistic Mathematics Education: an Example from a Longitudinal Trajectory on Percentage. Educational Studies in Mathematics, 54, 9-35.

Wigley, A. (1994). Models for mathematics teaching. In A. Bloomfield \& T. Harries (Eds.), Teaching and learning mathematics (pp 22-25). Association of Teachers of Mathematics.

\section{Appendix 1: Activities in worksheet 1}

a) You are to select one of the boxes $(A, B, C)$ you have in your group.

Cut the box, to have one of the shapes $\mathrm{A}^{\prime}, \mathrm{B}^{\prime} \& \mathrm{C}^{\prime}-$ these are called the nets of the boxes.

Measure the different edges on $\mathrm{A}^{\prime}, \mathrm{B}^{\prime}$, or $\mathrm{C}^{\prime}$ that you have chosen.

Write these measurements on the edges.

b) Carefully paste the $1-$ by-1 cm squares stickers neatly on the chosen net.

Count the number of these stickers that can be fitted.

You might find it useful counting these in the different parts of the shape and then add.

c) Compare the number of tiles in each part with the dimension of the part, and note your observation.

\section{Appendix 2: Activities in worksheet 2}

a) The figure on the activity sheet is a sketch of the Whites' living room. Draw the net.

b) Identify the walls on your net.

c) Estimate the number of 30-by-30 cm tiles that will cover the walls.

d) Identify the floor on your net.

e) Estimate the number of 30-by-30 cm tiles that will cover the floor, if the tiles are packaged in packs of 11 tiles.

You might find it useful to estimate the number of tiles in different parts of the shape and then add them together.

f) If a pack of floor tiles sells for R135 and a pack of wall tiles sells for R110, estimate the cost of the required tiles.

Be ready to explain to the class how you arrived at your answer.

“The best of science doesn't consist of mathematical models and experiments, as textbooks make it seem. Those come later. It springs fresh from a more primitive mode of thought, wherein the hunter's mind weaves ideas from old facts and fresh metaphors and the scrambled crazy images of things recently seen. To move forward is to concoct new patterns of thought, which in turn dictate the design of the models and experiments. Easy to say, difficult to achieve."

\section{Edward O. Wilson}

